\title{
An innovative cartographic concept - The Geodynamic Map of the Mediterranean
}

\section{Rationale of the map}

The collision between Eurasia and Africa-Arabia started in Paleogene times and is still active today. The recent geodynamics of the Arabo-Mediterranean domain are dominated by the progressive closure of remnant oceanic basins squeezed between the Eurasian margin and the Nubia (Africa) and Arabia plates. Various stages of consumption have been reached from Gibraltar to Oman, ranging from incipient inversion (e.g. the North African margin), to subduction (Mesozoic basins of the Eastern Mediterranean) and collision (e.g. the Zagros or Caucasus belts). Convergence is accompanied by deformation of both Eurasian and African margins, mostly as diffuse compression, but also as extension in short-lived basins and motion of blocks escaping towards the remnant oceanic spaces. The resulting kinematic pattern is quite complex. Western Mediterranean domain is merely accommodating the slow convergence of Nubia, whereas the still high convergence of Arabia in the Eastern domain has pushed Anatolia sideways, which is now laterally escaping to the west-southwest.

The aim of the Geodynamic Map of the Mediterranean, published in 2004 by the Commission for the Geological Map of the World (CGMW) is to produce a synthetic recent geodynamic view from several data sets concerning the tectonics, the kinematics and the volcanism of the Nubia-Arabia/Eurasia collisional region.

The challenge in gathering tectonics and kinematics into a single geodynamic map for the recent time is that the exact timing of many of the tectonic features involved remains largely unknown and that the kinematics is based on two different time scales, i.e. $3 \mathrm{Myr}$ for conventional kinematic models (or geological models) and tens of years for geodetic models. One way to avoid this difficulty would be to restrict the displayed data sets to seismic faults and geodetic motions, thus producing a seismotectonic map. But this would ignore the geologic evidences for tectonic features active during a period of time much longer than our instrumental records. On the other hand, the kinematics of major plates that controls tectonic evolution appreciably changed through time, even during the Quaternary. We thus selected a relatively short period of time, ranging from 300,000 years to Present. During this period, few major tectonics changes have been described, and we may assume that the kinematic pattern remained stable. This period includes the last two glacial stages, as well as the last interglacial and post-glacial periods. The corresponding deposits (glacial tills, river terraces, loess, marine terraces, shallow marine sediments, etc...) allow dating for some of the deformation of this age.

The selected area includes the entire convergent front between Nubia and Eurasia and the collision front between Arabia and Eurasia, as well as the whole Arabian plate. This convergence zone extends over 8,000 kilometers from the Atlantic to the Indian oceans. Since no obvious tectonic feature related to this collision exists north of latitude $52^{\circ} \mathrm{N}$, this parallel was chosen as the northern boundary of the map. The southern boundary was selected at latitude $8^{\circ} \mathrm{N}$ in order to keep the entire Arabia on the map. The western boundary of the map is longitude $13 . \mathrm{W}$, approximately marking the transition from pure transform motion (Gloria fault) to convergence. The eastern boundary at longitude $62^{\circ} \mathrm{E}$ marks the eastern limit of the EurasiaArabia collision zone and the westernmost extension of the EurasiaIndia subduction zone in Makran, including part of the Owen Fracture zone at sea.

The Geodynamic Map of the Mediterranean results from a compilation of regional published data. Numerous papers maps, catalogs and databases concerning the tectonics, kinematics, seismicity and volcanism have been considered. It consists of two sheets, Sheet
1- Tectonics and Kinematics; Sheet 2- Seismicity and Tectonics, both in the Mercator projection and at the same scale (ca. 1:10 M at the center of the map).

\section{Sheet 1. Tectonics and Kinematics}

\section{Tectonic features}

On this sheet, are represented several types of tectonic features, i.e. the different fault types and the major folds or .exures, as far as they respond to the criteria of age and size (see discussion below). Because of the scale of the map, faults smaller than $25 \mathrm{~km}$ (about 2 $\mathrm{mm}$ at the scale of the map) cannot be represented. As concerns the folds, the major restriction is the width rather than the length of the structure. In active folded and orogenic belts, long and narrow Late Quaternary anticlines and synclines commonly develop, such as in Zagros, Alborz, Dinarides, or along the major transform faults. At the scale of the map the solid lines representing the fold axes generally obscure the morphology of the structure on the map. Consequently, we chose to show exclusively the fold axes of large structures such as dome, flexure or wide anticlines. Accretionary ridges, transform faults, deformation fronts of accretionary prisms, strikeslip and thrust faults or blind thrusts are .gured by speci.c red symbols.

\section{Age criterion of the faults}

The set of fault presented on the map includes (1) the faults that have been activated or re-activated during historical times (the "active fault s.s." or "historic faults") or the faults seismically active, and (2) the faults that have been active during the last 300,000 years. The .rst category can be relatively easily reported at the scale of the map because they are generally well known thanks to the numerous seismotectonic studies. The shallow seismicity, presented on the sister map (Sheet 2), can be directly correlated with this .rst category of faults. The second category represents most of the faults of the map. They may correspond to faults belonging to the so-called "Holocene faults", "Late Quaternary faults", "Capable faults", "Potentially active faults" or "Active faults" of the literature. Rigorously, it includes the faults cutting formations belonging to the time slice, such as continental and marine sediments, and volcanics. Nevertheless, because of the paucity of these formations, with respect to the area covered by the map, it is generally difficult to assign precise ages to these Quaternary faults. Where Quaternary formations are lacking, the exact age of these faults is uncertain. The uncertainty on the age of the faulting is commonly large within the Quaternary and the authors generally distinguish the Quaternary faults from the Neogene ones. More detailed dating within the Quaternary is rarely available. We chose to show Quaternary faults even where a direct evidence of Late Quaternary activity is questionable, rather than to ignore them. Hence, some questionable faults may have been included as long as their age interval of activity is based on some reasonable data. Even where it is not possible to demonstrate if a fault has been reactivated during the last 300,000 years, we assume that a fault that has been active for the last millions of years and throughout the Quaternary is likely to have been active for the last 300,000 years. This assumption is substantiated by studies of active and Quaternary faults everywhere.

\section{Fault representation}

Faults are represented as solid red lines where well located and enough dated, and by dashed lines where approximately located or inferred, and/or where their ages are poorly constrained within the 
Quaternary. We distinguish normal (ticks on downthrown side), reverses (barbs on upper side) and strike-slip faults (arrows along fault indicate direction of lateral movement). In addition, we distinguish active blind thrusts (see Legend) where they are seismically active, and where Late Quaternary surface related deformations (.exures, uplift) have been evidenced. We do not classify the faults from their displacement rates. That results from the lack of reliable data concerning the displacement rates of most of the faults of the map. It means that the representations of minor faults, with a small displacement rates, and of major faults, with large displacement rates such as active plate boundaries, are similar. We only display the displacement rates inferred from kinematic models along the major transform faults marking plate boundaries (i.e. the Anatolian, Levant, and Owen faults).

\section{Geologic vs geodetic models}

Plate motions within the Arabo-Mediterranean domain have long been described in global kinematics models by the interaction of three major plates (Eurasia, Africa and Arabia). Although additional plates had long been recognized based on geology, faults and seismicity distribution (e.g. Somalia and Anatolia), the scarcity of data available for this type of modeling prevented of a reliable motion for these small plates. Motions of the major plates themselves were not very accurate, due to the need to use remote data from outside the Mediterranean (e.g. the Atlantic circuit to reach Africa-Eurasia motion). Rates in these global models were obtained from oceanic magnetic lineations, the modeled kinematics thus being a mean over a time interval sufficiently long to identify these lineations, namely $3 \mathrm{Myr}$. In this map, we refer to this type of kinematic modeling as "geologic model". Our knowledge of the presentday kinematics has been greatly improved by the accumulation of geodetic measurements during the last decades. Horizontal crustal motion can now be measured with high accuracy, and we now have access to an "instantaneous" kinematic over a time span of several tens of years. Geodetic models allow to reassess major plates motion and ultimately discuss the evolution of these motion through times by comparing mean motion for the last 3-Myr (geologic models) to geodetically measured motions. This is of particular importance for the Mediterranean region, since some of the major active structures may actually be younger than $3 \mathrm{Ma}$.

\section{Choice of the models}

The large number of kinematic models now available for the Mediterranean-Arabian domain precludes showing them all on a single map. NUVEL-1A was selected as the reference for geologic motion of Africa, to which we added Chu \& Gordon's model for the opening of the Red Sea, a model which is based on many more spreading rates estimates allowing the determination of the Danakil microplate motion. A difficulty with the geodetic solutions proposed for the Mediterranean is that they all use a different Eurasia frame of reference, depending on the number of stations actually located on Eurasia, and the own author's conception of stable Eurasia. To avoid this problem, we selected a self-consistent geodetic model (GSRM v1.2; Kreemer et al., 2003), which actually solves for the mis.t between the different reference frames of the different studies, as well as velocity .eld. We use the latest version of the GSRM model released in May 2004. The study includes 563 GPS horizontal velocities within the coordinates of our map, plus additional constraints on the direction and style of the strain rate .eld derived from seismicity. We checked that differences between this global model and other local geodetic solutions are small in the working area (i.e. $<2$ $\mathrm{mm} / \mathrm{yr}$ ), so that GSRM is representative of the available geodetic data.

\section{Crustal velocities}

We selected a limited number of locations to show crustal velocities. Nubia geodetic motion with respect to Eurasia is smaller than predicted by the 3 Myr geological plate model (NUVEL-1A) and slightly west of it. We thus choose to show both motions there. In the Western Mediterranean, this NW convergence is accommodated in a narrow seismic zone in North Africa continued offshore north of Sicily. We thus do not show any motion north of this boundary. Along the Hellenic Arc, east of the Kefallonia right-lateral transform, we show GSRM motion in a Nubia reference frame (Aegea/Nubia and Anatolia/Nubia convergence). In the Eastern Mediterranean, northward motion of Arabia drives deformation in Iran and adjacent areas. We show velocities with respect to Eurasia on some of the blocks that are considered as stable (e.g. Anatolia and Central Iran). Geodetic and geologic solutions are shown for Arabia kinematics, since geodetic measurements give a signi.cantly slower motion than geology. The possibility that both Nubia and Arabia slowed down between $3 \mathrm{Ma}$ and Present is still open to discussion. Since NUVEL-1A failed to propose a reliable motion for Somalia, we only show the geodetic model for Somalia kinematics. Somalia/ Nubia opening rate is $5 \mathrm{~mm} / \mathrm{yr}$ in the northern Ethiopian rifts. Motion along the Owen Fracture Zone (i.e. India/Arabia motion) is close to zero.

\section{Volcanoes}

The main map displays 237 eruptive centers (purple triangles) assumed to have been volcanic activity during the last 150,000 years.

\section{Geodynamic inset}

It summarizes the geodynamic features of the main map: the vectorial eld of plate motions, well de.ned plate boundaries, diffuse deformation zones, minor plates (e.g. Adriatic plate) or blocks (e.g. Danakil block).

\section{Sheet 2. Seismicity and Tectonics}

On this sheet, the earthquakes are displayed on the same tectonic pattern as sheet 1 . As a matter of fact, seismicity, the main cause of natural hazards in this region extending in the map from the Atlantic to the Indian Ocean and Caspian Sea, underlines the current tectonic activity. The earthquakes are plotted essentially from the International Seismological Center database and concern the period 1964-2003. Only relocated events have been considered. The epicenters have been represented using different symbols according to their magnitudes $(3-4.4 ; 4.5-5.4 ; \geq 5.5)$ and their focal depths $(0-50$ $\mathrm{km} ; 51-100 \mathrm{~km} ; 101-300 \mathrm{~km} ;>300 \mathrm{~km})$. Two insets are included in this sheet, one showing the Focal mechanisms, the other presenting a Tectonic sketch of the Mediterranean region with the age of the different small oceanic basins (remnants Mesozoic basins, Neogene basins) and post-orogenic basins (e.g. Tyrrhenian basin) along with the main tectonic features.

Eric Barrier, CNRS, Université Pierre \& Marie Curie, Paris, France Nicolas Chamot-Rooke, Ecole Normale Supérieure, Paris, France Guido Giordano, Università di Roma TRE, Roma, Italia Andrea Morelli, Istituto Naziolale di Geo.sica e Vulcanologia, Roma, Italia

Jean-François Brouillet, CNRS, Universitè Pierre \& Marie Curie, Paris, France

Set of 2 sheets: 1 -Tectonics and Kinematics; 2 -Seismicity and Tectonics First edition, (C)GMW, 2004

Projection: Mercator; scale: 1:13,000,000 at the Equator (ca. $1: 10,000,000$ at the center of the Map)

Size: $99 \mathrm{~cm}$ x $53 \mathrm{~cm}$ Price : 15 Euro

Note of the image: Previous double-page displays Sheet 1 (Tectonics and Kinematics) with its Geodynamic inset (lower left corner). An excerpt of the main map of Sheet 2 (Seismicity and Tectonics) was included as a lower central inset. The legend and auhorship do not appear here. 